\title{
Unmasking the Myths Surrounding Use of Barrier Face Coverings During the COVID-19 Pandemic
}

\author{
Chee Hwui Liew ${ }^{1,2}$, Gerard Thomas Flaherty, ${ }^{1, *}$ \\ ${ }^{1}$ School of Medicine, National University of Ireland Galway, Galway, Ireland \\ ${ }^{2}$ School of Medicine, Trinity College Dublin, Dublin, Ireland \\ ${ }^{3}$ School of Medicine, International Medical University, Kuala Lumpur, Malaysia
}

Corresponding Author: Gerard Thomas Flaherty, MD, FFTM, FISTM, Professor, School of Medicine, National University

of Ireland Galway, Galway, Ireland.Tel: +353-91495469, Email: gerard.flaherty@nuigalway.ie

Received August 26, 2020; Accepted September 4, 2020; Online Published August 26, 2020

\begin{abstract}
Face masks have been worn by members of the public for source control during pandemics and major outbreaks of infectious disease across the centuries. As the current coronavirus disease 2019 pandemic evolves, reluctance towards the wearing of face masks and anti-mask sentiments by some people have been encountered, with strongly held personal views and misinformation being disseminated through social media. Some of this resistance may arise from personal beliefs about the limited effectiveness of masks. Negative perceptions towards use of face masks have also been voiced by patients with pre-existing medical conditions such as chronic obstructive pulmonary disease and asthma. There are concerns that face coverings may not be suitable for children or individuals with autism. Health care professionals have an obligation to be advocates for this public health intervention. Individual patients' concerns about mask use should be sensitively addressed by countering misinformation with reliable evidence from the scientific literature.

Keywords: COVID-19, Pandemics, Face Masks, Respiratory Diseases, Autistic Disorder
\end{abstract}

Citation: Liew CH, Flaherty GT. Unmasking the myths surrounding use of barrier face coverings during the COVID-19 pandemic. Int J Travel Med Glob Health. 2020;8(4):134-136. doi:10.34172/ijtmgh.2020.23.

'...we shall every one be mask'd...' William Shakespeare

Love's Labour's Lost Act V, Scene ii (1588-1597)

Face masks have been used for source control during pandemics and major outbreaks of infectious disease for centuries. Although the use of masks in this particular scene did not relate to infection control, Shakespeare composed this and other great works during the so-called second epidemic of bubonic plague in the $16^{\text {th }}$ century. The iconic beak-like masks worn by 'plague doctors' during the bubonic plague pandemic in medieval Europe remind us of their time honoured role in infectious disease source control. A strong culture of face mask use has persisted in Asia, which was most severely affected by the severe acute respiratory syndrome (SARS) epidemic of 2002-2004. ${ }^{1}$ As the current coronavirus disease 2019 (COVID-19) pandemic evolves, reluctance towards the wearing of face masks by some members of the public has been encountered, with strong contrary opinions being disseminated through social media. Some of this resistance may stem from personal beliefs about the limited effectiveness of masks. Historically, this attitude also prevailed among "mask slackers" during the 1918 influenza pandemic. ${ }^{2}$ We have encountered negative perceptions in our own travel health clinic towards use of face masks among patients with pre-existing medical conditions such as asthma. In this article, we will attempt to address these unfounded fears by exploring the underlying evidence base for the safe and effective use of barrier face coverings, even in vulnerable patients with chronic respiratory disease.

\section{Evidence for Use of Face Coverings}

A meta-analysis of 21 studies reported that use of masks by health care workers and non-health care workers could reduce the risk of respiratory virus infection by $80 \%$ and $47 \%$, respectively. ${ }^{3}$ The important role of face masks and respirators in supporting physical distancing in both public and health care settings is supported by a further meta-analysis of 172 studies by Chu et al. ${ }^{4} \mathrm{~A}$ compartmental model for assessing the community-wide impact of mask use by the general public using data relevant to COVID-19 dynamics in the state of New York revealed that immediate, near universal (80\%)

Copyright $\odot 2020$ The Author(s). This is an open-access article distributed under the terms of the Creative Commons Attribution License (http:// creativecommons.org/licenses/by/4.0), which permits unrestricted use, distribution, and reproduction in any medium, provided the original work is properly cited. 
adoption of moderately effective masks could prevent $17 \%$ $45 \%$ of projected deaths over two months in New York, while decreasing the peak daily death rate by a remarkable $34 \%$ $58 \% .^{5}$

Lay person fears that face mask use somehow compromises ventilatory capacity are at odds with the results of several reliable studies. One such study showed that surgical mask use for one hour at a low-moderate work rate was not associated with significant subjective perceptions of exertion, thermal stress or clinically significant physiological sequelae, including oxygen desaturation. ${ }^{6}$ A more recent investigation concluded that surgical masks did exert an effect on ventilation, cardiopulmonary exercise capacity and comfort levels. ${ }^{7}$ This laboratory study involved exercise of a higher intensity, however, and failed to specify the ambient environmental conditions such as temperature and humidity which could have affected the physiological measurements.

A randomised controlled trial conducted in France showed that surgical mask use did not affect heart rate and oxygen saturation during a six-minute walking test (6MWT). ${ }^{8}$ Although varying degrees of dyspnoea were reported by participants, surgical masks did not present a barrier to completion of the test. While both surgical face masks and N95 respirators were found to influence temperature and humidity in the microclimate of the mask, the effects were much less pronounced with medical face masks than with respirators. ${ }^{9}$ These experimental studies provide reassurance that the use of medical masks under normal circumstances, which do not involve significant aerobic exertion, does not compromise normal cardiorespiratory parameters. Intolerance to wearing of medical masks is not likely to be related to an increased physiological burden, but may reflect surgical mask-related psychological effects such as personal discomfort, which may be expected to decline with persistent use.

\section{Safety of Face Mask Use in Patients With Underlying Diseases}

A study of 97 patients with chronic obstructive pulmonary disease (COPD) showed that, while all patients completed a 6MWT, a heightened caution may be indicated for mask use among those with more severe limitations (e.g. Medical Research Council dyspnoea scale scores of 3 or greater or $\mathrm{FEV}_{1}<30 \%$ predicted). This study assessed N95 rather than medical face masks, however. ${ }^{10}$ The use of protective face masks with greater breathing resistance than surgical masks (e.g. N95) in simulated work conditions has been shown to be tolerated physiologically by individuals with controlled respiratory disorders, including chronic rhinitis, mild COPD, and mild asthma. ${ }^{11}$

It is generally recommended to avoid the use of masks in children under the age of 2 years. The concern is that younger children may not follow instructions to wear masks correctly. Children's perceptions of face masks seem to be influenced by the face mask's design and perceived breathability. ${ }^{12}$ The travel health considerations for individuals with autism spectrum disorder have been discussed previously in this journal. ${ }^{13}$ Face masks may present sensory and social communication challenges to autistic children and adults, given that these individuals are highly sensitive to touch and may have difficulty making eye contact, preferring instead to focus on the lips during conversation. Conventional masks render lip reading impossible, which complicates communication efforts among autistic, deaf or partially deaf persons. These barriers can be addressed with appropriate measures, however, such as allowing the person with autism to select from among different types of fabric face masks, as well as wearing face masks with transparent plastic windows. ${ }^{14}$

Public health guidance recommends the use of washable and reusable cloth face coverings in non-health care settings. A recent review of 25 studies that examined the filtration properties of cloth face masks demonstrated that they are capable of providing clinically useful levels of filtration with the potential to reduce the spread of viruses such as SARS coronavirus 2 (SARS-CoV-2). ${ }^{15}$ The most protective materials were muslin, cotton and flannel, preferably in three to four layers and with a thread count of at least 100 threads per inch. Face shields or visors are an alternative for those who cannot, or refuse to wear, face coverings. In a simulation study, face shields were shown to reduce immediate viral exposure within 18 inches of a cough by $96 \% .{ }^{16}$ Face shields blocked $68 \%$ of small particle aerosols, which are not believed to be a dominant mode of transmission of SARS-CoV-2.

Risk compensation, or the paradoxical increase of highrisk behaviour after adopting a protective measure, has been invoked in some quarters to argue against the use of face coverings as a public health intervention. ${ }^{17}$ However, the available evidence does not validate concerns that wearing face coverings undermines other public health behaviours such as hand hygiene and physical distancing. The Centers for Disease Control and Prevention recommend against the use of face masks in children younger than 2 years, those who are experiencing respiratory distress, people who are exercising, or individuals who are unconscious, incapacitated or unable to remove their own mask. ${ }^{18}$ The World Health Organization does not proscribe the use of face masks, except during exercise, but it provides useful guidance on their safe use by the general public. ${ }^{19}$

\section{Conclusion}

We believe that the myths being propagated on social media about the potentially deleterious effects of wearing face masks during the COVID-19 pandemic are unfortunate and potentially dangerous. Health care professionals should sensitively address individual patients' and public concern about mask use by countering misinformation with reliable evidence from the recent scientific literature. Over four centuries have elapsed since Shakespearean plays were first performed, but the threat of pandemics is still with us and the use of face masks remains an important public health countermeasure.

\section{Authors' Contributions}

Both authors contributed equally to the conception, planning, writing and editing of the article. The final version was read and approved by both authors. 


\section{Conflict of Interest Disclosures}

The authors declare that they have no conflicts of interest.

\section{Ethical Approval}

Not applicable.

\section{Funding/Support}

None received.

\section{References}

1. Elachola H, Gozzer E, Rahman NMM, et al. Photo-epidemiology to estimate face covering use in select areas in Asia versus the Americas and Africa during the COVID-19 pandemic. J Travel Med. 2020. doi:10.1093/jtm/taaa121.

2. Hauser C. The Mask Slackers of 1918. The New York Times. 2020. https://www.nytimes.com/2020/08/03/us/mask-protests-1918. html. Accessed August 17, 2020.

3. Liang M, Gao L, Cheng $C$, et al. Efficacy of face mask in preventing respiratory virus transmission: a systematic review and metaanalysis. Travel Med Infect Dis. 2020;36:101751. doi:10.1016/j. tmaid.2020.101751.

4. Chu DK, AkIEA, Duda S, SoloK, YaacoubS, Schünemann HJ. Physical distancing, face masks, and eye protection to prevent person-toperson transmission of SARS-CoV-2 and COVID-19: a systematic review and meta-analysis. Lancet. 2020;395(10242):1973-1987. doi:10.1016/s0140-6736(20)31142-9.

5. Eikenberry SE, Mancuso M, Iboi E, et al. To mask or not to mask: modeling the potential for face mask use by the general public to curtail the COVID-19 pandemic. Infect Dis Model. 2020;5:293308. doi:10.1016/j.idm.2020.04.001.

6. Roberge RJ, Kim JH, Benson SM. Absence of consequential changes in physiological, thermal and subjective responses from wearing a surgical mask. Respir Physiol Neurobiol. 2012;181(1):29-35. doi:10.1016/j.resp.2012.01.010.

7. Fikenzer S, Uhe T, Lavall D, et al. Effects of surgical and FFP2/ N95 face masks on cardiopulmonary exercise capacity. Clin Res Cardiol. 2020:1-9. doi:10.1007/s00392-020-01704-y.

8. Person E, Lemercier C, Royer A, Reychler G. [Effect of a surgical mask on six minute walking distance]. Rev Mal Respir. 2018;35(3):264-268. doi:10.1016/j.rmr.2017.01.010.

9. Li Y, Tokura H, Guo YP, et al. Effects of wearing N95 and surgical facemasks on heart rate, thermal stress and subjective sensations. Int Arch Occup Environ Health. 2005;78(6):501-509. doi:10.1007/ s00420-004-0584-4.

10. Kyung SY, Kim Y, Hwang H, Park JW, Jeong SH. Risks of N95 face mask use in subjects with COPD. Respir Care. 2020;65(5):658664. doi:10.4187/respcare.06713.

11. Bansal S, Harber P, Yun D, et al. Respirator physiological effects under simulated work conditions. J Occup Environ Hyg. 2009;6(4):221-227. doi:10.1080/15459620902729218.

12. Smart NR, Horwell CJ, Smart TS, Galea KS. Assessment of the wearability of facemasks against air pollution in primary schoolaged children in London. Int J Environ Res Public Health. 2020;17(11). doi:10.3390/ijerph17113935.

13. Neo WX, Flaherty GT. Autism spectrum disorder and international travel. Int J Travel Med Glob Health. 2018;7(1):1-3. doi:10.15171/ ijtmgh.2019.01.

14. Thom R, Turner K. Helping People with Autism Spectrum Disorder Manage Masks and COVID-19 Tests. Harvard Health Publishing; 2020. https://www.health.harvard.edu/blog/helping-peoplewith-autism-spectrum-disorder-manage-masks-and-covid-19tests-2020061020089. Accessed August 17, 2020.

15. Clase CM, Fu EL, Ashur A, et al. Forgotten technology in the COVID-19 pandemic: filtration properties of cloth and cloth masks-a narrative review. Mayo Clin Proc. 2020;95(10):22042224. doi:10.1016/j.mayocp.2020.07.020.

16. Perencevich EN, Diekema DJ, Edmond MB. Moving personal protective equipment into the community: face shields and containment of COVID-19. JAMA. 2020;323(22):2252-2253. doi:10.1001/jama.2020.7477.

17. Mantzari E, Rubin GJ, Marteau TM. Is risk compensation threatening public health in the COVID-19 pandemic? BMJ. 2020;370:m2913. doi:10.1136/bmj.m2913.

18. Centers for Disease Control and Prevention (CDC). Considerations for Wearing Masks. CDC; 2020. https://www.cdc.gov/ coronavirus/2019-ncov/prevent-getting-sick/cloth-face-coverguidance.html. Accessed August 17, 2020.

19. World Health Organization (WHO). Advice on the Use of Masks in the Context of COVID-19. WHO; 2020. https://www. who.int/publications/i/item/advice-on-the-use-of-masks-in-thecommunity-during-home-care-and-in-healthcare-settings-in-thecontext-of-the-novel-coronavirus-(2019-ncov)-outbreak. Accessed August 17, 2020. 